\title{
The Survival Factors of Newly Created Firms in Tunisia (Case of the Sfax Region): An Analysis by the Mann-Whitney Wilcoxon Test
}

\section{Sahar Ayadi*}

Faculte des Sciences Economiques et de Gestion de Sfax, Universite de Sfax, Tunisia

\begin{abstract}
This research focuses on the factors of survival and growth of new enterprises in Tunisia. Based on previous research, we hypothesize that three factors influence the survival and growth of these firms: factors related to the entrepreneur, factors related to organizational characteristics and characteristics of the environment from start-up. We test these assumptions on a sample of 60 companies. The results show that human capital and the experience of the entrepreneur have a relatively small impact on the survival of newly created firms. Similarly, the intensity of preparation for creation by accompanying structures is not generally a key factor for survival. On the other hand, organizational characteristics (the amount of capital invested at start-up or customer structure) are strongly linked to the survival of the latter.
\end{abstract}

Keywords: Survival; Newly created firms; Growth factors

\section{Introduction}

The emergence of a new generation of entrepreneurs to alleviate unemployment in Tunisia is an economic priority in the face of a public sector with a low capacity for job creation and a weakening private sector.

One way to fight unemployment is to promote entrepreneurship. Moreover, the State has tried to promote entrepreneurship through the provision of support structures and support for the creation of companies. However, the average four-year mortality rate of new Tunisian firms is $40 \%$.

For this, our country needs today a new generation of entrepreneurs, giving new impetus to the national economy and changing the rules of the game in the private sector. We should seek today to promote a new entrepreneur who invests in high value-added sectors, which will have a favorable political and economic environment in order to ensure the survival and success of the newly created company.

Nevertheless, given that the entrepreneur's journey is risky and full of uncertainty, the latter risks abandoning his journey halfway. Therefore, it is not only a question of increasing the number of entrepreneurs in the country; but rather to study the sustainability of these jobs, as well as the sectors in which they are created. So some questions deserve to be asked: How does the entrepreneur achieve a successful business? Why do some companies succeed and others fail? And what are the factors that favor the survival of the newly created company?

These are questions to which we are tempted to provide answers in order to analyze the determinants of the success and survival of the newly created enterprises. However, in this paper, we will explore the criteria for the survival of. Then, in the second section, the key factors of survival of the new company are reached and the hypotheses of our research are advanced. We will identify our research methodology and how we will be able to validate or invalidate the assumptions of the survival of the young company. Finally, in the fourth section, we discuss the results of our research.

\section{Review of the Literature}

\section{Survival analysis}

The early years of a new company have been studied extensively by organizational development theorists. It is seen as a preliminary step leading to growth and leading to success and success [1]. Indeed, the start-up period is mainly criticized for the fragility of the created entity, it would be its youth which would represent the major risk and which would generate the problems to be solved. Daileurs, it is from the entry of companies in the start-up phase that sometimes precedes the creation process and its legal creation that it is possible to identify those that are newly created. Some authors describe this phase as a stage of survival (Churchill and Lewis) at the "valley of death". Indeed, it is the period when the failure rate is highest $[2,3]$. So the survival of the young firm is the minimum criterion, the first step, the necessary element in the access to the success of a company.

Entrepreneurship research focuses on survival as a period ranging from 1 to 3 years, which ultimately corresponds to the presumed duration of the start-up phase. Our field of study is limited to companies that are at the end of the start-up phase and have not exceeded the first five years of their existence [4]; in the pre-organization phase [5], or in the downstream phase of growth and expansion.

The duration of a project's survival refers to the period between the date of its actual creation and/or its commencement and the date of its closure or cessation of its activity. We take as the original event the start date of the activity of the companies created and as the last date, that of the cessation of activity.

\section{Key factors in the survival of newly created companies}

University studies and OECD research identify a list of factors that influence the survival rate of firms. While macroeconomic conditions, industrial cycles and existing market discriminations can have an impact on the survival of firms.

*Corresponding author: Sahar Ayadi, Faculte des Sciences Economiques et de Gestion de Sfax, Universite de Sfax, Tunisia-3018, Tel: +21650777843, 21644104152; E-mail: ayadisahar1@gmail.com

Received July 09, 2017; Accepted July 19, 2017; Published July 24, 2017

Citation: Ayadi S (2017) The Survival Factors of Newly Created Firms in Tunisia (Case of the Sfax Region): An Analysis by the Mann-Whitney Wilcoxon Test. Int $\mathrm{J}$ Econ Manag Sci 6: 438. doi: 10.4172/2162-6359.1000438

Copyright: (c) 2017 Ayadi S. This is an open-access article distributed under the terms of the Creative Commons Attribution License, which permits unrestricted use, distribution, and reproduction in any medium, provided the original author and source are credited. 


\section{Assumptions related to the manager}

Age of Entrepreneur: Older people are more likely to have work experience, so firms run by older people have higher survival rates [6]. However, at the same level of experience, a young entrepreneur has a better chance of survival.

Education: the higher the entrepreneur's level of education, the better the company's performance and the better the survival rate. In addition, the diploma of the project bearer gives chances of survival and pass the course of the third year of activity. In addition, a qualified entrepreneur is more likely to have a perennial business than an inexperienced entrepreneur.

Experience: Relevant past experiences (self-employed or selfemployed activities in the same sector or occupation) are likely to increase the chances of survival $[7,8]$. Data suggests that this factor has no impact.

Similarly, the experience of an entrepreneur has a stronger impact on female creators. The perennial firm rate by experienced women is higher than those run by experienced men. This experience must be longer than three years; otherwise experience does not influence sustainability. On the contrary, Lan Gowitz and Minniti explain that women have less self-confidence than men in making business development decisions. This is why men's ability to survive than women. The survival rate is higher by creators formerly employed by the same sector or business owner than those who were unemployed or students [9].

The financial resources of the entrepreneur: the more a small independent firm has its own financial capital available to the firm (the self-financing of the entrepreneur), the more likely it is to succeed [10]. However, small firms are less likely than large firms to have access to sufficient capital.

As for the entrepreneur's capital, many researchers emphasize the importance of initial capital to ensure the survival and success of the business. However, Wagner found that the higher the capital intensity, the greater the chance of its survival. Other researchers such as Berryman, Keasy, Cressy [11] choose a financial approach and specify the importance of a solid financial basis for the survival of newly created societies.

\section{Assumptions related to the characteristics of the newly created company}

It can be called birth at its start. In survival and growth, it transforms and modifies its structure, thus organizing its maturity.

First, early survival studies focused on two characteristics of the firm, age and height. Evans was one of the first to demonstrate that age and size increase the likelihood of survival of a firm. However, more recent studies suggest that the rate of change in firm size would be more influential the survival of the company. The analysis carried out by INSEE on the three and five-year survival of companies created in the form of Ex Nihilo of the 2006 generations show that a company created in the form of a company and all the more likely to be perennial Individual business.

\section{Age of enterprise}

Small and new enterprises often have more limited resources and capacity than large firms. This is why newly created small firms have higher death rates than large firms (Mata and Portugal, Mitchell,
Sharma and Kesner, Cook et al). But if the company seeks to develop, it must seek a competitive advantage to position itself on the market. The survival and development opportunities offered to each company also depend on its competitive position: relevance of the market segmentation, relative quality of supply, level of competitiveness.

\section{Innovation capacity}

Entrepreneurs whose activities are based on new products, services or technologies face a greater risk of rejection of their products by markets than those who market already accepted products, services or technologies. So innovation capacity is associated with a higher death rate.

Baum demonstrates that firms increase their chances of life by making innovation research alliances; the degree of centrality on the research network impacts the performance of the firm. Start-ups would benefit from making alliances for Have access to information and skills that allow for better performance. In addition, collaboration with public partners such as universities, high schools and schools is more likely to survive.

\section{The role of employees and product development capacity}

Business development theories assume that the business grows through the acquisition of new productive assets and/or the hiring of personnel under the direct disposal of the company, Entrepreneur, therefore it is to acquire "raw" production capacities to adapt them to the specific needs of the company (it is an internal learning of new resources that tend to make these new capacities specific to the needs of the company ' business). Product development is an important aspect of the development of new enterprises. To this end, Eisenharst and Lymman argue that developing a portfolio of new products is necessary for new firms to put in a quick cash inflow, gain external visibility and legitimate rapid trade from where Increase in the probability of survival concerning cosmetics, human health and pharmacy.

\section{Assumptions centred on the company environment}

The choice of location: For Jacob and Quel, opening up to a local market results in growth that develops according to a proximity strategy and which operates essentially in a market where uncertainty is low and where needs are not sophisticated. Which leads to a lower degree of innovation and less widespread use of business practices. On the other hand, the firm that opens up to an international market is more innovation-oriented, giving more importance to the development of new products as well as to the improvement of existing production methods. Aimed at a well-developed organizational structure in order to satisfy the requirements of importers De Toni and Nassimbeni point out that the environment in which the young firm is located can promote growth. Such as the case of a young company sheltered by a nursery; the latter provides support logistics, assistance and linkage with a network of technical and commercial partners. Therefore, it is considered a stimulating growth location. Similarly, companies in a dense and resource-rich environment (notably cognitive), which can generate significant savings and, above all, have a positive influence on the growth of young companies.

Flexibility to competition: The inverse and taking into account this positive effect of the territory, the intensity of competition associated with a high local density of establishment of the sector of the young enterprise could tend to penalize its growth. The measure of survival is the subject of a wide-ranging debate and depends on different estimates of the evolution of variables such as profit, assets, fixed assets, 
value added, employment, sales or it can be measured by the increase in turnover, without necessarily Employment and vice versa. Similarly, there may be growth in turnover and deterioration in value added [12]. Thus, the phenomenon of survival is multifactorial insofar as there is not a single causal factor but a conjunction of favorable factors note that the need for survival has two dimensions. The first is the need to ensure competitiveness, or simply the survival of the company. This "objective" need for growth is particularly marked when the company suffers from a dimension that is less than the optimal minimum size of its sector and is thus penalized in terms of costs vis-à-vis its competitors.

Indeed, the need to reach "critical size" can also arise from the importance of R\&D or communication investments that the company must make to stay in the race. The second dimension of the need for growth is a more psychological one. It refers to the place of growth in the objectives of the manager of the company.

Social capital: It is increasingly accepted by the scientific community that entrepreneurial activity integrates the social relationships of entrepreneurial networks that allow them to access the resources they need more easily by being in a way or 'another better connected these days. The literature clearly indicates that social capital, or the resources that entrepreneurs can access through their personal network, enable the entrepreneur to identify opportunities [13], mobilize resources and build the legitimacy of their enterprises [14].

It is also known that social networks influence economic performance. A network is a social structure composed of individuals (or organizations) called nodes that are connected by one or more types of interdependencies (professional, friendship, kinship).

Social networks influence the flow and quality of information because actors prefer to trust people they know. Trust, defined by Granovetter [15] as the certainty "that others will do things well" develops within the networks. Individuals need confidence.

Granovetter argues that social networks allow the development of social capital, access to information, the discovery of opportunities, etc. They are made up of weak links and strong ties. While weak links provide access to wider information, strong personal relationshipbased relationships improve co-operation between structures or individuals and problem solving.

The amount of capital invested at start-up: According to the Court of Auditors, firms with high capital at start-up have a higher probability of surviving than those with low financial resources [16-18].

For Starbuck, survival is not a spontaneous or random phenomenon, but rather a result of a combination of factors linked in particular to the characteristics of the company, its strategic positioning, but also to the financial structure and its operating constraints. This is the consequence of a decision, such as creating employment for the decision maker and increasing production in response to a stronger demand or in order to stimulate demand.
Carpenter and Peterson show that the lack of capital limits the probability of survival as well as the rate of growth. In this regard, Becchette and Trovato, Riding and Haynes, show that the availability of capital through debt and bank lending and by the contribution of equity was very important factors in promoting the survival and growth of the firm [19].

\section{Research Methodology and Sample}

\section{Research model}

Choice of the research model: We identify the effect of factors related to the entrepreneur, the company and the environment that influence survival is studied.

$Y$ (The survival of the newly created firm) $=\beta 0+\beta 1$ (Business characteristics) $+\beta 2$ (Environmental effect) $+\beta 3$ (Entrepreneurial resource characteristics $+\mu \mathrm{t}$.

H1: The characteristics of the newly created company have a positive influence on the survival of the new company.

$\mathrm{H} 2$ : The characteristics of the environment of the newly created company have a positive influence on the survival of the company.

H3: The Resource characteristics of the entrepreneur of the newly created enterprise have a positive influence on the survival of the company (Table 1).

Choice of the sample: An attempt was made to interview 60 entrepreneurs who had lived with their companies for more than three years and reached the first five years. Only companies that are in a startup situation and who have not exceeded their fifth birthday and meet the criteria for novelty and small size will be affected by the study. The selection of cases was also carried out in terms of internal diversity as a heterogeneous group composed of different sectors [20].

The sample studied then included 60 entrepreneurs from different academic backgrounds who created micro- or small enterprises, located in urban areas of the Sfax region. Tunisian crafts and Tunisian pastry, the technology sector (software implementation for example), the catering sector and the services.

We used a questionnaire with a 5 point likert scale. The variable of the entrepreneur is measured by 6 items. The variable of the company is measured by 8 items and the variable of the environment is measured by 6 items. Finally the independent variable which is survival, it is measured by two items that are the age and size of the firm $[21,22]$.

\section{Results}

\section{Data measurement and analysis}

First, we used the "SPSS20" software to explain the results obtained using the data collected. First, a major component analysis will be performed, and then the reliability of the scales will be verified through

\begin{tabular}{|c|c|c|}
\hline Items of the new business factor & Items of the environmental factor & Items of the Business Resource Factor \\
\hline Company Age & Choice of location & Age of the entrepreneur \\
\hline Company size & Intensity of competition & Self-financing \\
\hline Activity area & Accompanying structures & Family Support \\
\hline Role of employees & Bank support & Network of friends \\
\hline Innovation capacity & Role of suppliers & Social Capital: Business and Information Network \\
\hline Product quality/Price & Role of clients \\
\hline Franchise of brand & & \\
\hline
\end{tabular}

Table 1: Choice of the research model. 
the Cronbach alpha coefficient. Then, we will test the assumptions of our model and finally we will present the descriptive analyzes to describe the characteristics of the company and the entrepreneur.

Second, the correlation that represents the link between the variables is used: the endogenous variable which is the survival of the newly created firm and the exogenous variables are the characteristics of the firm, the motivation of the entrepreneur and the Resources available. The correlation is measured by a linear correlation coefficient. The value of this coefficient is between $(-1)$ and (1). If the value of this coefficient tends to $(-1)$, then the variables are strongly correlated and vary in the same direction.

Third, regression analysis has been used. Indeed, it is a statistical method that is based on the study of the correlation between the variables. In the simplest cases, we are interested in studying. The linear relation between an independent variable and a dependent variable. In addition, linear regression analysis describes the variations in the variable to be explained associated with variations in the explanatory variables [23-26].

Moreover, for the threshold of acceptance of the Cronbach coefficient, as specified in the previous section, for the exploratory nature of the research, we retain the value of 0.55 as the minimum threshold of significance. It should be noted that this coefficient is used in metric, proportional, or interval scales. However, some scales of ordinal type or Likert, as is the case in this research, are most often considered as metric scales $[27,28]$.

\section{Search results}

Measurement of the continuity and survival of newly created enterprises: For the study of the scale "Continuity and survival of the companies" we mobilized 9 items. A first coefficient of Cronbach gives us a satisfactory result that is 0.970 and 0.6 for internal consistency analysis. We have continued the factor analysis. The ACP, initially procured, required a rotation of the axes. We then obtained the results presented below. As can be seen in Table 2, we have only $71.09 \%$ of the total variance.

The analysis carried out in this research is based on two parts. The

\begin{tabular}{|c|c|c|}
\hline & & Contribution F.1 \\
\hline 1 & Role of employees & 0.97 \\
\hline 2 & Product (Quality/Price) & 0.859 \\
\hline 3 & Market share & 0.833 \\
\hline 4 & Choice of location & 0.832 \\
\hline 5 & High financial capital & 0.818 \\
\hline 6 & Franchise of brand & 0.84 \\
\hline 7 & A capacity for innovation & 0.799 \\
\hline 8 & Flexible competition & 0.705 \\
\hline & & \%de la variance expliqué $71.09 \%$ \\
\hline
\end{tabular}

Table 2: Continuity and survival of the companies. first is to check the change in the degree of continuity and survival of the newly created enterprises in the S-fax region according to the characteristics of the enterprises, the environmental factors and the financial resources of the entrepreneur. Nonparametric tests are applied (inequality of variances and non-normality) (Tables 3-6).

At this level, we have chosen to adopt an analysis of the nonparametric variance factor, and ordinal variables, guided us towards the implementation of non-parametric tests (the MannWhitney Wilcoxon)

The rank of these values obtained by a classification (or even an interclassification) of the set of observed values. The question then is whether the differences observed in the sub-samples bear with a sufficiently low risk of error (risk of first species).

$\mathrm{H} 0$ corresponds to the hypothesis of homogeneity, or if, conversely, they contradict it $(\mathrm{H} 1)$.

Nonparametric tests will then be applied. The aim is to study the quality of the causal relationships between the variable to be explained and the explanatory variables formulated in the research hypotheses.

As a first step, we will focus on verifying assumptions about changes in business continuity and survival based on business characteristics (industry, product/service quality, and team of employees).

The impact of company characteristics on the continuity and survival of newly created enterprises: To test the hypothesis concerning the variability of the continuity and survival of businesses by force or not the industry, we operationalized the Mann-Whitney Wilcoxon two sample groups ( $1=$ life of a force in the sector of activity, $0=$ absence of a force in the sector of activity).

The goal is to determine the extent to which the survival of firms changes according to the strength of the industry. The rank test by industry shows that the mean score for the sample of the presence of force in the industry is 28.14 , while that of the absence sample of sector strength of activity is 24.58 .

The result of the Mann-Whitney Wilcoxon equal scores is significant at the $10 \%$ level $(\mathrm{p}<0.088)$. This reflecting the continuity and survival of businesses change depending on the strength of the industry. We only conclude the sector of activity with significant assessments on the continuity and survival of the newly created companies $[29,30]$.

To test the variability of the continuity and the survival of the companies according to the strength of the quality of the product/ service, we mobilized a test on the ranks of the scores. The result of the latter reveals an average rank score of 26.29 for the group of companies with strength of their product/service quality and 26.89 for the sample of companies not having strength of their product/service quality. The difference in mean score between these two samples is not significant

\begin{tabular}{|c|c|c|c|c|c|c|c|c|}
\hline & \multicolumn{2}{|c|}{ Number of observation } & \multicolumn{2}{|c|}{ Sum of scores } & \multirow{2}{*}{$\begin{array}{c}\text { Average } \\
\text { M1 }\end{array}$} & \multirow{2}{*}{$\begin{array}{c}\text { scores } \\
\text { M2 }\end{array}$} & \multicolumn{2}{|c|}{ Mann-Whitney Test } \\
\hline & N1 & N2 & Sc1 & SC2 & & & $\mathbf{Z}^{*}$ & p-value \\
\hline Company area & 28 & 24 & 788 & 590 & 28,14 & 24.58 & $3.836^{\star}$ & 0.088 \\
\hline Quality/Price of product/service & 34 & 18 & 894 & 484 & 26.29 & 26.89 & -0.138 & 0.891 \\
\hline Role of employees & 17 & 34 & 492 & 834 & 28.94 & 14.53 & $4.022^{* *}$ & 0.027 \\
\hline
\end{tabular}

**Significant coefficient at the threshold of $5 \%$.

*Significant coefficient at $10 \%$ threshold (Ns) non-significant coefficient.

$\mathrm{N} 1$ : number of observations for companies that attach great importance to the sector of activity, quality of product/service, and team of employees

N2: number of observations for companies that do not attach importance to the sector of activity, product/service quality, and team of employees.

Table 3: Measurement of the continuity and survival of newly created enterprises. 


\begin{tabular}{|c|c|c|c|c|c|c|c|c|}
\hline & \multicolumn{2}{|c|}{ Number observation } & \multicolumn{2}{|c|}{ Sum of scores } & \multicolumn{2}{|c|}{ Average scores } & \multicolumn{2}{|c|}{ Mann-Whitney } \\
\hline & N1 & N2 & SC1 & SC2 & M1 & M2 & $\mathbf{Z}^{*}$ & p-value \\
\hline Local Implementation & 37 & 15 & 925 & 453 & 25 & 30.2 & $2.145^{\star}$ & 0.092 \\
\hline Regional Implementation & 27 & 24 & 700 & 626 & 25.93 & 26.08 & -0.039 & 0.943 \\
\hline Exports & 7 & 44 & 173 & 1153 & 14.71 & 26.2 & $6.81^{* *}$ & 0.02 \\
\hline Number of clients & 22 & 29 & 598 & 728 & 27.18 & 25.1 & $-0.506 \mathrm{Ns}$ & 0.613 \\
\hline suppliers & 16 & 35 & 474.5 & 851.5 & 29.66 & 14.33 & $5.215^{\star *}$ & 0.034 \\
\hline Public Conventions & 17 & 35 & 423 & 955 & 24.88 & 17.29 & $7.548^{* * *}$ & 0.004 \\
\hline Business franchise & 16 & 35 & 418.5 & 907.5 & 26.16 & 25.93 & -0.052 & 0.959 \\
\hline
\end{tabular}

***Significant coefficient at threshold of $1 \%$,

${ }^{*}$ Significant coefficient at the threshold of $5 \%$,

*Significant coefficient at the threshold of $10 \%$,

Ns: Non- significant coefficient.

Table 4: Characteristics of the entrepreneur.

\begin{tabular}{|c|c|c|c|c|c|c|c|}
\hline \multirow{2}{*}{} & \multicolumn{2}{|c|}{ Number of observation } & Somme scores par ranges & \multicolumn{3}{|c|}{ Moyenne des scores } & \multicolumn{2}{|c|}{ Test de Mann-Whitney } \\
\cline { 2 - 7 } & N1 & N2 & SC1 & SC2 & M1 & M2 & Plus-value \\
\hline Support structures & 31 & 25 & 855 & 741 & 27.58 & 29.64 \\
\hline Financial start-up & 42 & 13 & 317.5 & 1222.5 & 29.11 & 14.42 & $7.398^{\star *}$ \\
\hline Social capital & 43 & 13 & 1304.5 & 291.5 & 30.34 & 22.42 & 3.54 \\
\hline
\end{tabular}

***Significant coefficient at threshold of $1 \%$,

**Significant coefficient at the threshold of $5 \%$,

*Significant coefficient at the threshold of $10 \%$,

Ns: Non-significant coefficient,

$\mathrm{N} 1$ : number of observations for companies that attach great importance to the financial and material arrangement of the entrepreneur,

N2: number of observations for companies that do not attach any importance to the financing and material of the contractor.

Table 5: Observations for companies.

\begin{tabular}{|c|c|c|c|}
\hline & Coefficients & t-stat & p-value \\
\hline Area company & $0.756^{*}$ & 2.331 & 0.053 \\
\hline Role of employees & $1.12^{* *}$ & 2.437 & 0.045 \\
\hline Local implementation & $0.303 \mathrm{~ns}$ & 1.382 & 0.209 \\
\hline Exports & $1.331^{* *}$ & 2.55 & 0.038 \\
\hline suppliers & $0.29 \mathrm{~ns}$ & 1.018 & 0.342 \\
\hline Agreements with public campanies & $0.918^{*}$ & 2.151 & 0.069 \\
\hline Support structure & $-0.286 \mathrm{~ns}$ & -1.539 & 0.168 \\
\hline Financial capital at start-up/self & $0.598^{* *}$ & 2.859 & 0.024 \\
\hline Social network & 0.97 & 3.401 & 0.011 \\
\hline Constant & $-3.28 \mathrm{~ns}$ & -1.35 & 0.217 \\
\hline Fisher & 8.849 & & \\
\hline Ajusted $\mathrm{R}^{2}$ & $51 \%$ & & \\
\hline
\end{tabular}

***Significant coefficient at threshold of $1 \%$,

**Significant coefficient at the threshold of $5 \%$,

*Significant coefficient at the threshold of $10 \%$,

Ns: Non-significant coefficient.

Table 6: Coefficient factors

$(p<0.891)$. Consequently, the quality of the product/service has no appreciation for the continuity and survival of the companies.

The result of the Mann-Whitney Wilcoxon equal scores obtained showed that two staff team groups vary in terms of the continuity and survival of businesses. The probability of being wrong in rejecting the hypothesis Nil is below the threshold of $0.05 \%(\mathrm{p}<0.027)$.

We conclude that the team of employees with significant assessments on the continuity and survival of newly created companies.

The impact of conditions linked to the business environment on the continuity and survival of newly created companies: The second step we wanted to verify logically is the hypothesis that the continuity and survival of firms can change according to environmental conditions and values (local location, regional location, and export, number of customers, suppliers, and Agreement with public enterprises).

To test the variability of the newly created firms' survival according to each environmental condition, we used a test on the ranks of the scores on the two groups of the sample.

( 1 =favorable environmental condition)

( $0=$ unfavorable environmental condition)

The test of rank scores on the local implantation confirms the rejection of the null hypothesis. This hypothesis is confirmed for the exact test $(\mathrm{p}<0.092)$ at the risk of $10 \%$.Indeed, there is a significant relationship between the local presence and the continuity of the newly created companies.

The use of the same test on the variability of the survival of firms according to export shows that there is a significant difference between the two opinions (favorable/unfavorable) in terms of export. The Wilcoxon test indicates a value of $6.81(\mathrm{p}<0.02)$. We can conclude that exporting significantly affects business continuity and survival.

As for suppliers, the Mann-Whitney Wilcoxon test is significant, and therefore the assumption that suppliers affect the continuity and survival of newly created companies is verified.

Finally, the test on rank scores, provided on the basis of the agreement with public enterprises is significant at the $1 \%$ threshold $(\mathrm{p}<0.004)$. The continuity and survival of firms change according to the agreement or not with the public companies

The impact of the financial and material resources of the entrepreneur on the continuity and survival of the newly created company: The test of the scores of the ranks on the three indicators of the assembly of the financial file (structures of support and financing 
like the bank credits, the subsidies and the BTS). Besides, financing the equipment of the new company, the material means and the layout of the new enterprise during the first years of the life of the company. Thus the results of our research confirm the rejection of the null hypothesis. Indeed, the Wilcoxon test has a value of 4,478 at the $5 \%$ threshold $(\mathrm{p}<0.043)$. In other words, there is a significant effect of support structures on the continuity and survival of new firms.

To check the variability of continuity and survival of firms according to the importance or not of the financial capital at the start. That is to say that self-financing of the entrepreneur and his responsibility towards third parties during the first years of the life of the company.

The result of the latter shows a ranking score of 29.11 for the sample of companies that attach great importance to the financial capital of the entrepreneur and 14.42 if they do not attach importance to the financial capital of the founder.

The difference test on average score between these two business samples, taking into account the variable "financial capital at start-up", and significant at the $1 \%$ threshold. The same test of the importance of the social capital of the entrepreneur, that is to say the relational network that favors the life of the company. Indeed, some banks provide credit to entrepreneurs because of close relationships.

This test indicates a significant mean score difference in terms of continuity and survival of the newly created firms, the Wilcoxon test has a value of $3.56(\mathrm{p}<0.069)$. These results show that the assumption that continuity and Survival of newly created companies change according to the importance given to the financial and material setup is fully valid.

N1: number of observations for companies that attach great importance to the financial and material arrangement of the entrepreneur.

N2: number of observations for companies that do not attach any importance to the financing and material of the contractor.

Measurement of the model with multiple regressions: In order to test factors influencing business continuity and survival, we used multiple regression tests at three levels:

Entrepreneur's financial arrangement) on the survival of firms, which is calculated using the correlation coefficient $\mathrm{R}$.

The quality of the fit of the model, which is assessed through the coefficient R2, as well as the Fischer test F. 2 must also take into account the number of explanatory variables and observations assimilated by the model. For this purpose, the adjusted R-2 allows a more realistic appreciation of the results of the model. The multiple regression test, in this regard provided a significant result.

Indeed, the value $\mathrm{F}$ is 8.849 with a probability $\mathrm{p}$-value $=0.0041$. It makes it possible to decide on the quality of the value between the two variables.

At this stage, we verified three main relationships: the company characteristic, the environmental condition, and the financial and material arrangement of the contractor at the start.

The first review of the relationship between industry and business survival reveals a significant test. Indeed, the test shows a coefficient of the order of 0.756 at the risk of $10 \%(p<0.053)$. The results also reveal a significant relationship between the team of employees and the survival of firms. The multiple regression tests shows a significant coefficient at the $5 \%$ threshold and allows us to conclude the acceptance (H1) Proposing that the characteristics of the company significantly influence their survival and in particular increase the continuity and survival of newly created projects.

The second relationship we studied concerns the influence of environmental conditions on the continuity and survival of firms (H2). However, the relationship between linkage and absorption capacity indicates a significant test, the test reveals a positive and significant coefficient of dependence of 1.33 for the export variable, respectively, and a positive and significant coefficient of 0.918 for the variable "agreement with public enterprises".

On the other hand, the results show that the two variables conceived on the side of the "local implantation" and the "suppliers" have insignificant effects on the continuity and the survival of the companies. In this regard, we conclude that the hypothesis (H2) is partially validated. The last relationship we wanted to verify logically returns to the hypothesis $(\mathrm{H} 3)$ relative to the influence that can have the financial arrangement of the entrepreneur on the continuity and the survival of the enterprises. The multiple regression tests provided a significant result. The results show that the two variables "financial capital at start-up" and "social capital" positively and significantly affect the survival of newly created firms at the $5 \%$ threshold. However, these results are frustrated by a non-significant effect on the part of the Support structure on the survival of enterprises. Thus the hypothesis (H3) which postulates that the survival of newly created firms depends on the financial and material arrangement of the entrepreneur is partially validated.

\section{Conclusion}

The aim of this work was to explore the survival factors of newly created firms. To do this we have mobilized the survival theories of the newly created company while taking into account theories that analyze the success and failure of newly created companies.

This research led us to conclude that this literature often combines the success of the company with success. This eliminates the explanation of the entrepreneur's figure and focuses on what ends up. So this research is part of the analysis of the facts of the entrepreneur, his actions to lead his business life.

The survival of the company can be well explained by the links established by the entrepreneurs between them and distant markets and the analysis of the role of export agents. Moreover, intense competition marks horizontal relationships between new firms, which are all the stronger as barriers to entry are low. However, the latter can be achieved in areas such as the technical training services sector or in the case of large companies benefiting from capacity subcontracting. These include the benefits of market access and skilled labor, the use of advanced technologies and the desire to benefit other less developed counterparts, and intensive inter-firm cooperation.

Concerning the strategy of companies, especially SMEs, is strongly conditioned by the profile of the entrepreneur, as Julien and Marchesnay have shown. Perceptions and decisions are influenced by entrepreneurs' economic preferences and social references. As demonstrated, for example, Bertrand in his thesis. Despite its structural weaknesses the new company has the highest growth rate dynamism that can be assessed in terms of job investment. Besides, cheap labor is of quality.

From a methodological point of view, we used the Mann Witney 
Citation: Ayadi S (2017) The Survival Factors of Newly Created Firms in Tunisia (Case of the Sfax Region): An Analysis by the Mann-Whitney Wilcoxon Test. Int J Econ Manag Sci 6: 438. doi: 10.4172/2162-6359.1000438

Wilcokson methd because of qualitative data and nonparametric tests were applicable. Thus, our research can be described as both qualitative and exploratory.

\section{Research Perspectives}

The work carried out in this paper has important methodological, theoretical and technical limitations. First of all in terms of methodology, our bias towards the qualitative approach suffers from the recurring criticisms addressed to this method and even more so when it is integrated into techniques very little accepted in the community such as the Mann-Whitney test Wilcoxon. This is why we are looking for a more adequate method of data analysis. In the same vein, our choice of semantic analysis and comprehensive interpretation based on the interpretative paradigm suffers from similar reservations. On the other hand, our posture of disciplinary transversality combining various social and human sciences is reprehensible from superficiality. This is part of the risks incurred and assumed in the exploratory phase of research, the apprentice-researcher who wants to discover the scientific home in all the latitudes.

Moreover, the specific legal and financial status of new firms reduces comparative protocols for large enterprises. Finally, to a lesser extent, the quantitative and qualitative shortcomings of the available data as well as the sample may undermine the credibility of the approach as well as the results of the research.

On the theoretical level, since the study of the determinants of the success of the company is linked to failure, a whole field of study remains to be explored in the field of space science. In addition, analyzing the firm's praxeology in the temporal dynamics requires other methodological orientations, such as extending the sample to other entrepreneurs in various branches of activity, as well as involving other territorial players and different stakeholders directly involved. With regard to certain studies on the available resources of new enterprises, some appear, and at times confirm, sometimes nuance the results of our life stories. Our interpretations lead us to approach the theory of resources to the theory of organizational development.

However, non-economic factors such as the concept of social capital, is defined as "the non-financial part of the company's assets", the desire to succeed, for example. On the empirical level, an important work of deepening should be carried out within a multidisciplinary team, with the help of mixed software in order to analyze the quantitative and qualitative analysis data.

\section{References}

1. Benavent C, Verstraete $T$ (2000) Entrepreneurship and NICT - construction and regeneration of the business model". In: Verstraete $T$ (ed.) Entrepreneurial History - The Realities of Entrepreneurship, Paris, Management and Society.

2. Lorrain J, Dussault $L$ (1988) Entrepreneurs and opportunists: A comparison of their management behaviors. SME International Journal 1: 157-176.

3. Cressy R (2006) Why Do Most Firms Die Young? Small Business Economics 26: $103-116$.

4. Gartner WB, Bird BJ, Starr JA (1992) Entrepreneurship Theory and Practice. Entrepreneurship Theory and Practice 13: 13-31

5. Gartner WB (1989) Who is an Entrepreneur? Is the wrong question. Entrepreneurship Theory \& Practice 13: 47-68.

6. Furdas M, Kohn K (2011) Why Is Start-up Survival Lower Among Necessity Entrepreneurs? A Decomposition Approach. IZA Discussion Paper.

7. Luk STK (1996) Success in Hong Kong: Factors Self-Reported by Successful Small Business Owners. Journal of Small Business Management 34: 68.
8. Cooper AC, Gimeno-Cac son FJ, Woo CY (1994) Initial human and financial capital as predictors of new venture performance. Journal of Business Venture 9: 371-395.

9. Court of auditors (2012) Devices to support business creation, Evaluation Report for the National Assembly, Evaluation and Public Policy Review Committee 4.

10. Cooper AC, Artz WA (1995) Determinants of Satisfaction for Entrepreneurs. Journal of Business Venturing 10: 439-457.

11. Cooper AC, Gascon J, Woo C (1991) A Resource-Based Prediction of New Venture Survival and Growth. Academy of Management Proceedings, pp.113-119.

12. Dahlqvist J, Davidsson P, Wiklund J (2000) Initial Conditions as Predictors of New Venture Performance: A Replication and Extension of the Cooper et al. Study; Enterprise \& Innovation Management Studies 1: 1-17

13. Bhagavatula S, Elfring T, Van TA, Van DBGG (2010) How Social and Human Capital Influence Opportunity Recognition and Resource Mobilization in India's Handloom Industry. Journal of Business Venturing 25: 245-260.

14. Elfring T, Hulsink W (2003) Networks in Entrepreneurship: The Case of HighTechnology Firms. Small Business Economics 21: 409-422.

15. Granovetter M (2005) The Impact of Social Structure on Economic Outcomes Journal of Economic Perspectives 19: 33-50.

16. Baccari E (2006) Entrepreneurial motivations of young entrepreneurs in Tunisia: Exploratory study. $8^{\text {th }}$ International Francophone Congress on Entrepreneurship and Small Business (CIFEPME), University of Applied Sciences, Friborg, Switzerland.

17. Cook R, Campbell D, Kelly C (2012) Survival Rates of New Firms: An Exploratory Study. Small Business Institute Journal 8: 35-42.

18. Cressy $R$ (1994) The importance of human resources in the creation and survival of enterprises. Paper presented at EUROPMI Conference.

19. DeCastro J, Szyliowicz D (2004) Entrepreneurial Failure? The Factors That Predict Voluntary vs. Involuntary Exit. Frontiers of Entrepreneurship Research, Babson College.

20. Deprez S (2010) New companies five years later: more than one out of two still active in 2007, Insee Première.

21. Duchesneau DA, Gartner WB (1990) A Profile of New Venture Success and Failure in an Emerging Industry. Journal of Business Venturing 5: 297-312.

22. Survey (2009) Generation 2009 Three Years After, Insee Results, No. 51.

23. Enterprising Women (2012) Growth Survey, Highlights 2011, 2012.

24. Everett J, Watson J (1998) Small Business Failure and External Risk Factors Small Business Economics 11: 371-390.

25. Gartner W (1993) Words lead to deeds to an organizational emergence vocabulary. Journal of Business Venturing 8: 231-239.

26. Gartner WB (1985) A Conceptual Framework for Describing the Phenomenon of New Venture Creation. Academy of Management Review 10: 696-709.

27. GEM (2011) 2010 Women's Report. Global Entrepreneurship Monitor.

28. Gérard A, Kokou D (2001) Entrepreneurial coaching and construction of key success factors pp. 20-21.

29. Granovetter M (1985) Economic and Social Structure: the problem of embeddedness. American Journal of Sociology 91: 481-510.

30. Lussier RN, Shaike M (1996) A Business success versus failure prediction model for the retail industry. The Mid-Atlantic of Business 32: 79-92. 